\title{
EPIDERMOLYSIS BULLOSA
}

\author{
BY \\ W. H. MCDANIEL \\ From the Royal Belfast Hospital for Sick Children
}

(RECEIVED FOR PUBLICATION FEBRUARY 26, 1954)

Epidermolysis bullosa is a disease in which bullous skin lesions appear spontaneously or in response to mild trauma. The condition is seen in varying degrees of severity but, in all its forms, it is an incapacitating disease. Those suffering from the milder manifestations find any form of manual work difficult because of the painful bullae, produced by slight injuries, and children who are severely affected may not reach adult life. The condition is, fortunately, uncommon. Greenberg (1944) saw five cases of epidermolysis bullosa among 2,281 skin lesions, an incidence of $0 \cdot 2 \%$. Of 58,200 dermatoses seen at various skin out-patient clinics in hospitals in Northern Ireland during the past five years seven were examples of epidermolysis bullosa.

The following family is presented because of the extreme severity of the manifestations.

\section{Case Histories}

Henry M., the father of this family (Fig. 1), is one of six siblings, all of whom are normal; there is no history of bullous skin disease either in his parents or in his four parental aunts. His wife is unaffected; she is one of eight siblings, all normal, and there is no history of the condition in any of her 14 aunts and uncles. It was also ascertained that Henry M's grandparents and all his grandfather's family were normal. No blood relationship between Henry M. and his wife could be traced.

The child of the first pregnancy was severely affected at birth and feeding was difficult because of lesions in the mouth and on the lips. Bullae spread rapidly to involve almost the entire body surface; these became infected and the child died on the thirteenth day.

The second and third pregnancies ended in miscarriages.

Harry, born in May, 1942, the child of the fourth pregnancy, showed bullae in the mouth and on the fingers at birth, and bullae continued to appear after slight trauma on various parts of his body. His mother believed that occasionally some lesions appeared spontaneously. The hands showed uncomplicated but extensive bulla formation until about the age of 3 years. His father states that about this time, on an occasion when the child stumbled, his hands were grasped to

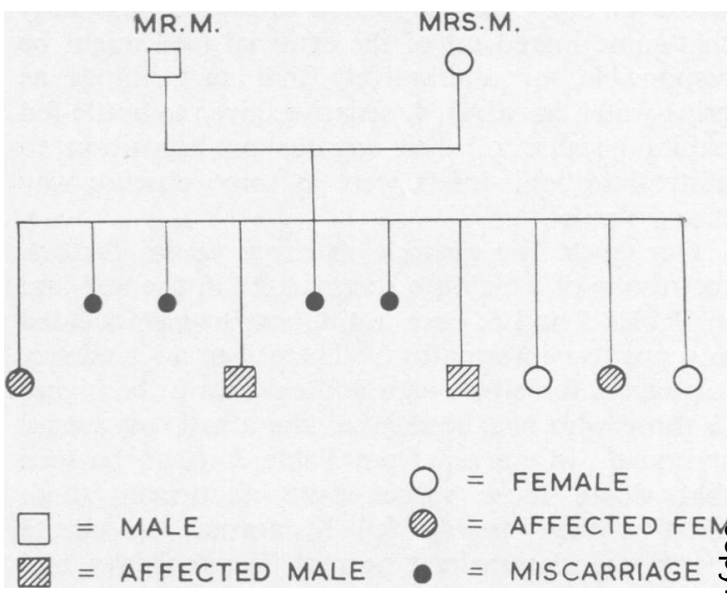

Fig. 1.

prevent him falling, and the skin peeled off the hands and fingers 'like a glove'. On healing, the hands presented the appearance seen in Fig. 2. The digits of both hands were completely flexed and enclosed in a

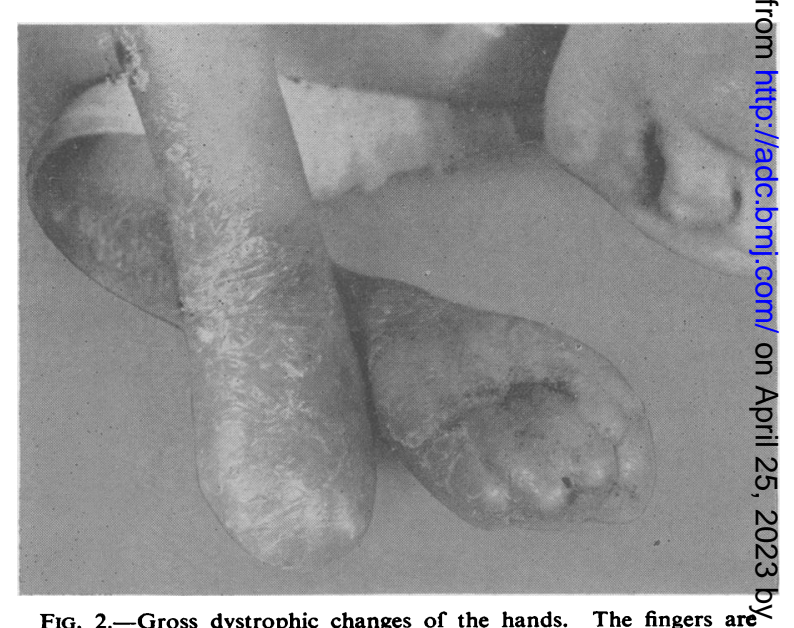

FIG. 2.-Gross dystrophic changes of the hands. The fingers are tightly fused in a clenched fist position and the fist is covered with tight envelope. Finger movements were possible underneath this envelope. 


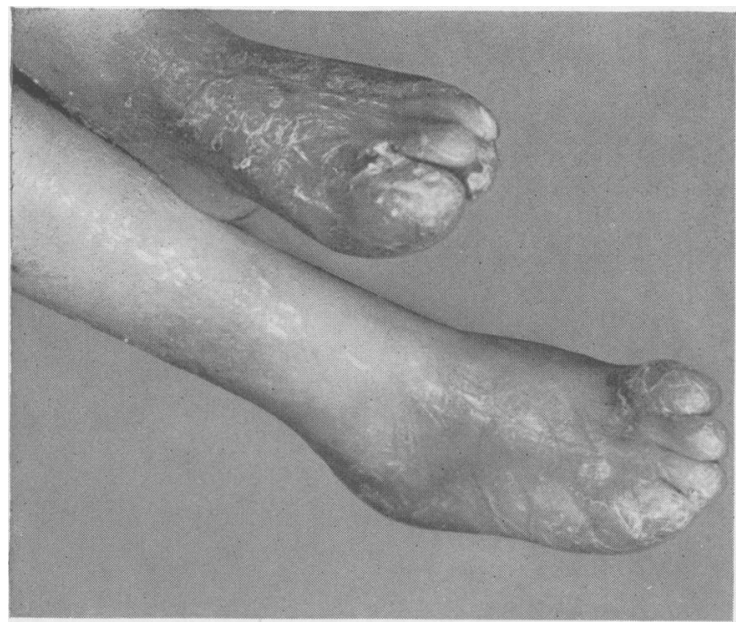

FIG. 3.-Dystrophic changes of the feet with fusion of toes. Condition before operation.

thin, semi-transparent, mitten-like membrane; very slight movements of the fingers were still possible. The toes were fused in a similar position of flexion (Fig. 3). There were scattered scars elsewhere on the body. The right cornea showed slight scarring. The hair was normal, but at the age of 6 all the nails (present at birth) had been lost and the teeth were grossly carious. There were bullae and ulcers in the mouth. The skin showed no dermographism. There was excessive sweating of the forehead. The child was fretful and difficult, and suffered considerably from pain, especially when the ulcerated areas were being dressed. Estimation of his level of intelligence was difficult as little attempt had been made to educate the child and, of course, he was unable to use his hands and fingers; it was thought, however, that he was at least of average ability.

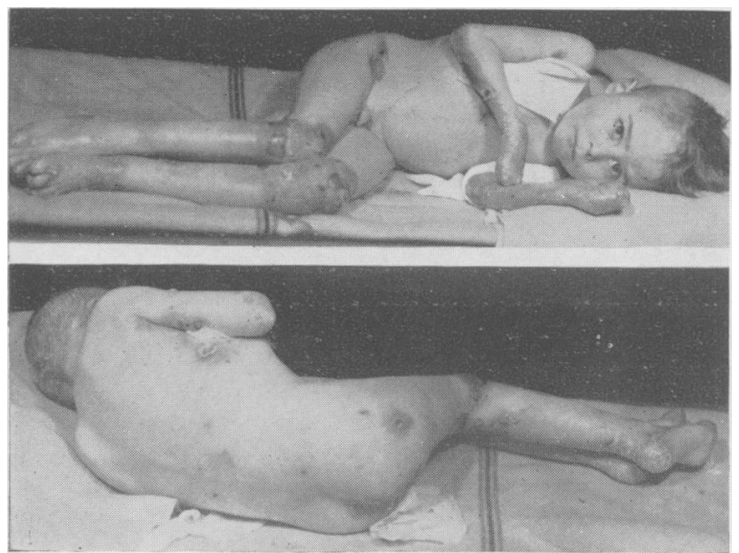

FIG. 4.-Gross dystrophic changes in the hands and feet. Gross scarring of hands, feet and knees. Many fresh bullae on various parts.
Tests for urinary porphyrins in August, 1949, and May, 1950, by Waldenström's test were negative, as were serological tests for syphilis. Blood counts showed only a moderate iron-deficiency anaemia.

In 1949, when the child was 7 (Fig. 4), a surgical attempt was made to free the fingers and toes from their confining membranes. First the toes were dissected apart and each dressed separately with paraffin-gauze; these healed satisfactorily but some fusion recurred in the depths of the web spaces. Some weeks later the hands were operated on, one at a time. The enclosing epidermal envelopes were stripped off; the digits were loosely adherent to one another and to the palm. They were separated by blunt dissection and each one dressed with paraffin-gauze. In spite of efforts made to maintain

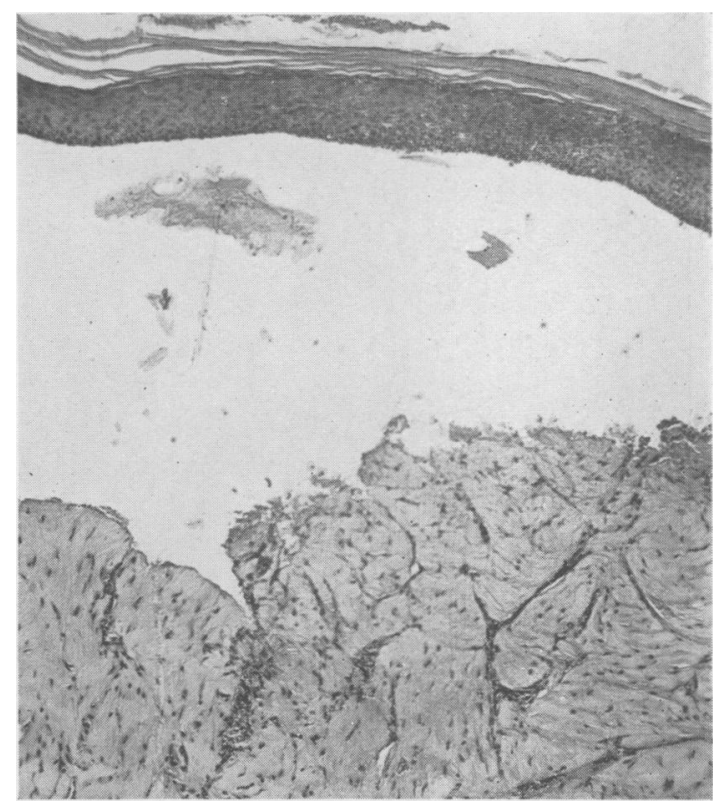

Fig. 5.-The thin, but otherwise normal, epidermis of the foot has become separated from the dermis. The latter shows an excess of mucoid connective tissue and absence of skin appendages in this particular section.

extension it was necessary, later, to do some further dissection to correct flexion deformities and to open up web spaces which tended to close. Skin grafting was not attempted. After some weeks the digits became individually enclosed in newly formed epidermis (presumably from islands of basal cell layer left behind after the 'envelope' had been removed). Histological examination of the membrane showed it to consist of rather thin but otherwise normally formed epidermis without any dermal adnexae (Figs. 5 and 6). These findings and the results of operation are very similar to those reported by Kitlowski and Banfield (1948) in a similar type of case. Unfortunately, over the next two years, the fingers, as a result of fresh bullae, gradually resumed their former condition of flexion and fusion. 
Harry died of pneumonia in 1952.

The fifth and sixth pregnancies ended in miscarriages.

Tony (Fig. 7), the result of the seventh pregnancy, was born in August, 1945. This child was, apparently, not so severely affected at birth as Harry, but at the time of writing his hands present much the same picture as did those of his elder brother. His finger nails are missing, or small and dystrophic; the hair is normal; his eyes, apart from a convergent squint, show no abnormality. There is no dermographism and no hyperhidrosis. He has, in general, been more easily managed than was Harry.

Anne, born in June, 1947, is perfectly normal.

Geraldine (Fig. 8) was born in February, 1949. At birth she had blood-filled bullae around the mouth and on the fingers and toes; at this time the nails were quite

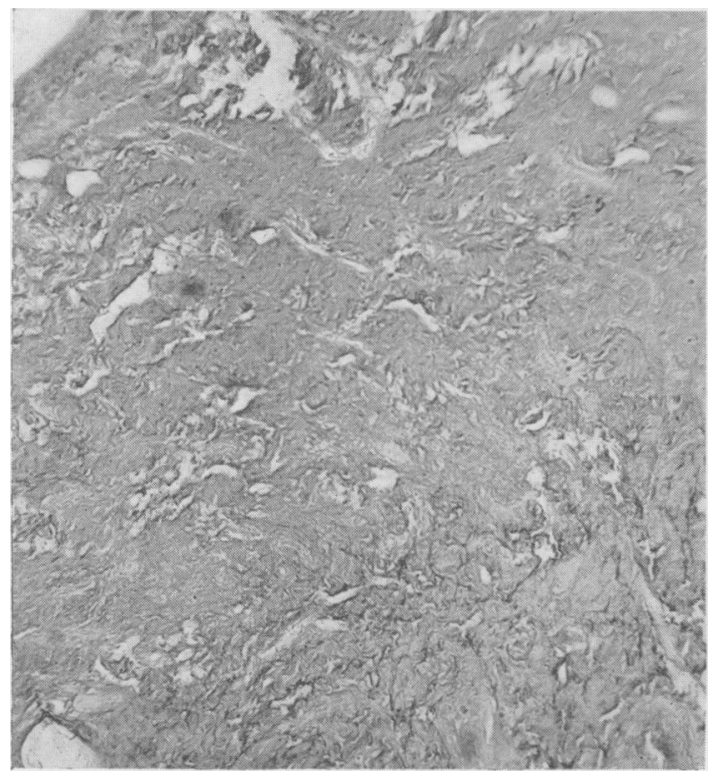

FIG. 6.-An attempt to demonstrate the absence of elastic tissue in the upper half of the dermis. The lower right hand corner of the photograph is representative of the lower half of the dermis. Here the elastic tissue stains normally. (Weigert's elastic tissue stain.)

normal. Hair and eyes are normal. This child appears to be less severly affected than her brothers but, at the time of writing, her hands are beginning to show the usual picture of flexion and fusion of the fingers within a confining envelope.

A girl, born in March, 1951, is quite normal.

\section{Discussion}

There is general agreement that epidermolysis bullosa is a hereditary condition, and Cockayne (1933) has classified the condition into three groups: (1) Epidermolysis bullosa simplex, transmitted as a dominant trait, appearing in infancy or childhood in

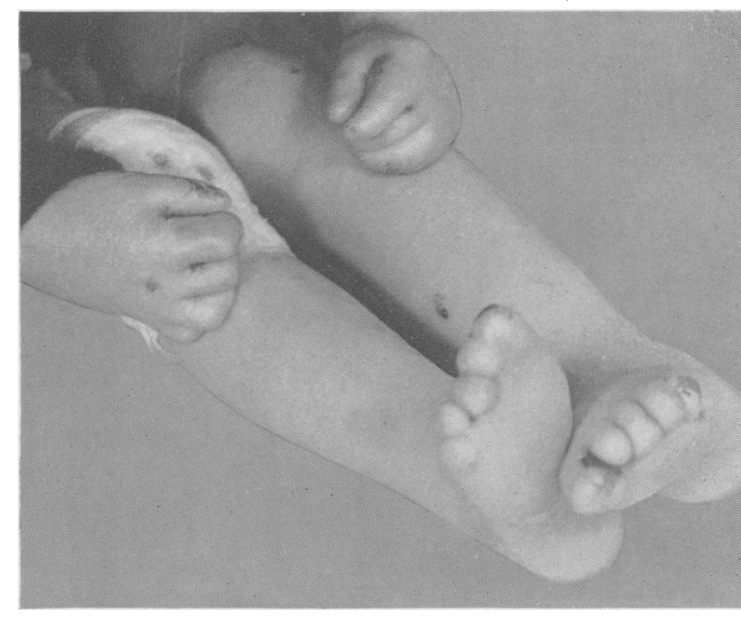

Fig. 7.--Dystrophic changes in the hands and feet, early fusion of toes, loss of nails.

otherwise normal children and manifested as bullae which arise mainly on the extremities in response to trauma, and which heal rapidly leaving thin scars. (2) Epidermolysis bullosa dystrophica, of which there are two forms, $(a)$, that which is transmitted as a dominant trait (and which has been called by Touraine (1942) epidermolyse bulleuse hyper-

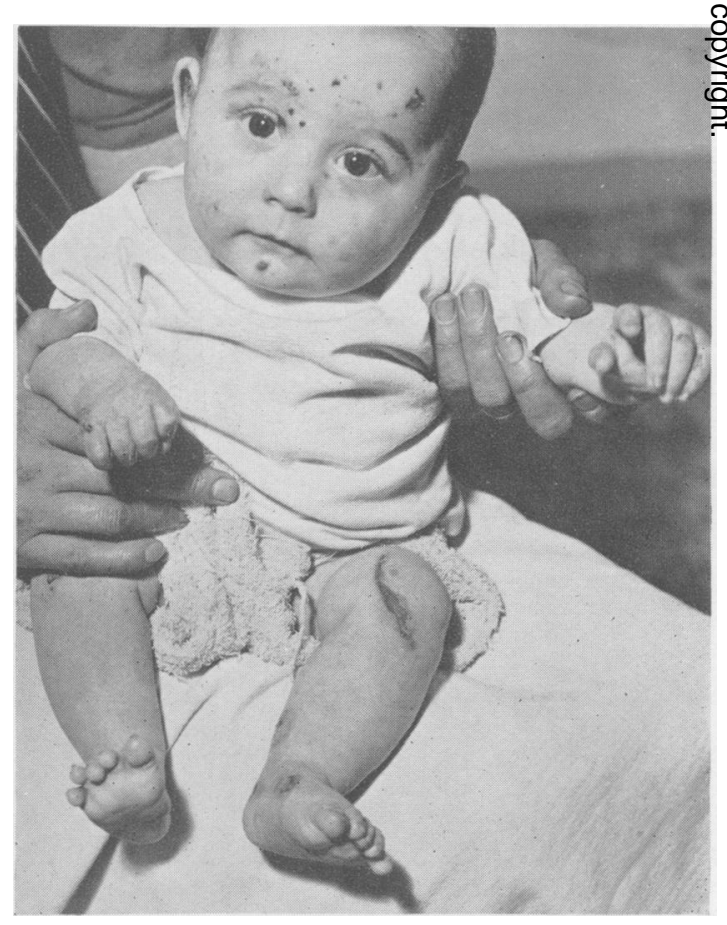

FIG. 8.--Geraldine M. with fresh bullous lesions on limbs and face. 
plasique), and (b), that which is transmitted as a recessive trait (Touraine's epidermolyse bulleuse polydysplasique).

The dominant dystrophic form appears at birth or soon afterwards in children who are otherwise normally developed, physically and mentally. Skin lesions usually heal with little scarring but lesions of the buccal mucosa may lead eventually to a leukoplakia-like atrophy.

The recessive dystrophic form is the most severe type of the disease; patients suffering from this are under-developed and below average in intelligence; the bullae are often large, filled with blood-stained fluid and are usually present at birth. On healing, keloidal scars and contractions may occur. Mucosal lesions are common and there are frequently associated congenital defects of teeth, nails and hair; there may be a general deficiency of body fat. Many of these children die in infancy and it is rare for any to reach adult life. The cases described here appear to fall into this group.

Aetiology. Several theories have been put forward to explain the aetiology of the condition, but none is entirely satisfactory.

Elliot (1895) suggested a sudden excessive exudation of fluid into the skin due to 'irritability of the cutaneous vascular system'. Wende (1904) thought that there was some fault in development of the rete cells and a lack of proper trophic innervation of the skin. More recently Winer and Orman (1945) have shown that the appearance of bullae, in a case of epidermolysis bullosa affecting the feet only, could be prevented by supportive elastic bandages; they suggested that there was an inherent defect in the vessel wall. Some cases have been described in which there was elevation of urinary porphyrins (Turner and Obermayer, 1938). Engman and Mook (1906) showed an absence of elastic fibres in the papillary and sub-papillary layers of the dermis. Later Kanoky and Sutton (1910) demonstrated this same deficiency in traumatized and undamaged skin. Ormsby and Montgomery (1943), however, express the view that it is difficult, pathologically, to conceive that the disease results from faulty development of elastic tissue'. Biopsy specimens, taken at operation from the feet of Henry M., show this absence of elastic tissue in the superficial layers of the dermis (Fig. 6).

\section{Summary}

A family, showing the features of severe recessive dystrophic epidermolysis bullosa, is described. Four out of the total of six children were affected. One died within two weeks of birth and another has died at the age of 10 years.

I should like to thank Dr. Ivan H. McCaw and Dr. J. Martin Beare for their assistance and encouragement in the preparation of this paper.

\section{REFERENCES}

Cockayne, E. A. (1933). Inherited Abnormalities of the Skin and Its Appendages, p. 18 et seq. London.

Elliot, G. T. (1895) J cutan Dis $13,10$.

Engman, M. F. and Mook, W. H. (1906). Ibid., 24, 55.

Greenberg, S. I. (1944). Arch. Derm. Syph., Chicago, 49, 333.

Kanoky, J. P. and Sutton, R. L. (1910). J.Amer. med. Ass., 54, 1137. Kitlowski, E. A. and Banfield, E. E. (1948). Plast. reconstr. Surg., 3,481 .

Ormsby, O. S. and Montgomery, H. (1943). Diseases of the Skin, 6 th ed., p. 432. Philadelphia.

Touraine, M. A. (1942). Ann. Derm. Syph., Paris, 8 series, 2, 309. Turner, W. J. and Obermayer, M. E. (1938). Arch. Derm. Syph., Chicago, 37, 549 .

Wende, G. W.'(1904). J. cutan. Dis., 22, 14

Winer, M. N. and Orman, J. M. (1945). Arch. Derm. Syph., Chicago, 52, 317. 